\title{
WIND-INDUCED RESPONSE CONTROL MODEL FOR HIGH-RISE BUILDINGS BASED ON RESIZING METHOD
}

\author{
Se Woon $\mathrm{CHOI}^{\mathrm{a}}$, Ji Hyun SEO ${ }^{\mathrm{b}}$, Hong Min $\mathrm{LEE}^{\mathrm{c}}$, Yousok KIM ${ }^{\mathrm{d}}$, Hyo Seon PARK \\ ${ }^{a}$ Department of Architecture, Catholic University of Daegu, 712-702 Keongsan-si, South Korea \\ ${ }^{b}$ Urban \& Building Science Research Team, GS E\&C Research Institute, 449-831 Yongin-si, South Korea \\ ${ }^{c}$ Industrial Engineering Dept., Samsung Engineering, 134-090 Seoul, South Korea \\ ${ }^{d}$ Center for Structural Health Care Technology in Building, Yonsei University, 120-749 Seoul, South Korea
}

Received 20 Apr 2012; accepted 27 Aug 2012

\begin{abstract}
A variety of methods have been applied to reduce the effect of the wind-induced vibration of a high-rise building as the excessive wind-induced vibration at the top of a high-rise building can cause physical and psychological discomfort to the user or the residents. For structural engineers, the most effective approach to control the wind-induced responses of high-rise buildings would be to control the stiffness or natural frequency of the building. This paper presents a practical design model to control the wind-induced responses of a high-rise building. In the model, the stiffness of a high-rise building is maximized to increase the natural frequency of the building by the resizing algorithm. The proposed design model is applied to control the wind-induced vibration of an actual 37 -storey building during the initial stage of its structural design.
\end{abstract}

Keywords: high-rise building, serviceability design, wind-induced vibration, resizing algorithm, structural optimization.

\section{Introduction}

Buildings can be vibrated by earthquakes and wind. The duration of earthquake-induced vibration is relatively short and related to the safety of building structures such as the risk of collapse. To reduce the earthquake damage, methods that dissipate the earthquake energy transmitted to the buildings using the dampers or that reduce the earthquake energy applied to the buildings using the isolators are used (Lee et al. 2009; Marshall, Charney 2012; Sayani et al. 2011; Taflanidis, Jia 2011). On the other hand, the duration of wind-induced vibration is relatively long compared to that of earthquake-induced vibration and is related to the serviceability of building structures (Kijewski, Pirnia 2007).

Generally, in high-rise buildings, the wind load rather than the earthquake load acts as a critical design condition (Kim, Kanda 2008). Recently, due to the development of construction technology and high-strength materials, the height of high-rise buildings has increased and the weight has lessened. These factors make high-rise buildings sensitive to wind. Therefore, it is important to control the wind-induced vibration of high-rise buildings. To reduce the effect of wind-induced vibration, a variety of methods have been applied to the structural design of these buildings. These methods include an aerodynamic design of the buildings' shapes, control of the damping ratios, and the application of an effective structural system (Kareem et al. 1999).

An aerodynamic design pertaining to the shape of a building seeks to reduce the wind-induced responses of high-rise buildings by changing the shape of the building. Examples of the common aerodynamic design include the modification of the corner geometry of a building, the addition of openings to a building, and the control of the building aspect ratio. The second method generally employed to reduce the wind-induced responses of high-rise buildings is associated with the use of additional damping devices such as viscoelasticity dampers, fluid dampers, tuned liquid dampers, and tuned mass dampers (Lewandowski, Grzymislawska 2009; Patil, Jangid 2011). For structural engineers, both of the aforementioned methods are not always considered as a practical and feasible solution, since the decision to change the shape of a building and to use additional damping devices cannot be made by the structural engineer alone but instead require the consent of the owner and the architect.

Therefore, for structural engineers at the initial phase of the structural design, the most effective approach to control the wind-induced responses of highrise buildings would be to control the stiffness or natural

Corresponding author: Hyo Seon Park

E-mail: hspark@yonsei.ac.kr 
frequency of the building. It is known that the level of the wind-induced vibration of a high-rise building with a natural frequency range of $0.1 \sim 1.0 \mathrm{~Hz}$ can be assumed to be inversely proportional to the natural frequency of the building (Tallin, Ellingwood 1984; Griffis 1993). Tallin and Ellingwood (1984), Chan and Chui (2006), and Chan et al. (2009) have proven that the wind-induced response can be reduced by increasing the natural frequency of a building.

As such, it would be necessary for structural engineers to have a practical method to increase the stiffness or natural frequency of a high-rise building without a significant increase in the structural weight or construction cost. Traditional trial-and-error based structural design methods may not be practical and efficient for structural engineers since a high-rise building is composed of numerous structural members to be designed and designers do not have enough information about which members are active to the natural frequency. The information about the active members may be obtained through a complicated process to solve the functional formula of the mass and stiffness of all structural members in a high-rise building, as the natural frequency is determined through a combination of the mass and stiffness of all structural members.

Research on design methods for the wind-induced vibration of high-rise buildings has been actively carried out. Chan and Chui (2006), Chan et al. $(2009,2010)$ proposed optimal design methods to minimize the structural weight or cost while satisfying the serviceability condition using cross sections of members as a design variable. They used the Optimality Criteria (OC) as an optimization tool. OC has a weakness in that it modifies the cross sections of members using a recursive resizing algorithm until the optimality criteria are satisfied while also requiring a sensitivity analysis. Li et al. (2011) presented an optimal wind design method using a micro-GA. This approach minimizes the structural cost subjected to the constraints on the displacement and acceleration. This requires a recursive analysis and an excessive amount of computation time. Petrini and Ciampoli (2012) presented a probabilistic framework for the performance based wind design of high-rise buildings. It probabilistically evaluates the relationship between the velocity of wind and the performance of the high-rise building. It requires an iterative analysis to calculate the probability and is difficult to apply to practical work.

In this paper, a practical design method based on the resizing algorithm, which does not require an iterative structural analysis, is presented to control the windinduced responses of a high-rise building. In the resizing algorithm, active members, which have a relatively large influence on the magnitude of the lateral stiffness or the natural frequency to be controlled, are selected and the cross sections of the active members are resized. The proposed design method is applied to control the wind-induced vibration of an actual 37-storey building during the initial stage of its structural design.

\section{Evaluation of the wind vibration}

The wind-induced vibration of a high-rise building is evaluated mostly in terms of the root-mean-square (RMS) acceleration or the peak acceleration under extreme wind conditions as specified in various codes (ISO 6897 1984; NBCC 1995; ASCE 2006; AIJ 2004; Solari 1982; Boggs 1997; Cermak 2003). Due to the aerodynamic effects of the wind, a high-rise building vibrates not to the alongwind direction alone but also to the cross-wind and torsional directions. Consequently, to check the serviceability of a high-rise building under the action of wind loads, an evaluation of the wind-induced vibration needs to be performed on those directions.

There are two approaches for structural engineers to evaluate the wind-induced vibration of a building (Kijewski, Kareem 1998). In the first and more common approach, the wind-induced vibration may be estimated using simplified equations (NBCC 1995; ASCE 2006; AIJ 2004). Several codes and standards permit predictions of the wind-induced responses of a building using simplified equations during the preliminary design phases. However, there are limitations when seeking to predict the wind-induced responses precisely through simplified equations, as a high-rise building subjected to wind loads shows complex behavior due to the vortex effect and the interaction between the building and the wind.

In the practical structural design of a high-rise building with a relatively large building aspect ratio, more accurate methods of predicting the wind-induced responses are used. The most accurate mean of predicting the windinduced responses of a high-rise building is to perform a wind-tunnel test during the initial design phase. Presently, one of the most commonly used evaluation methods for wind load and wind-induced responses in a windtunnel test is the High Frequency Force Balance (HFFB) method (Cermak 2003; Tschanz, Davenport 1983). In the HFFB method, the aerodynamic wind force spectrum is directly measured by the wind-tunnel test. The wind force spectrum measured by the wind-tunnel test, as shown in Figure 1, is used to estimate the wind-induced responses of a building analytically using the random vibration theory. The vertical axis in Figure 1 has a physical trend that is

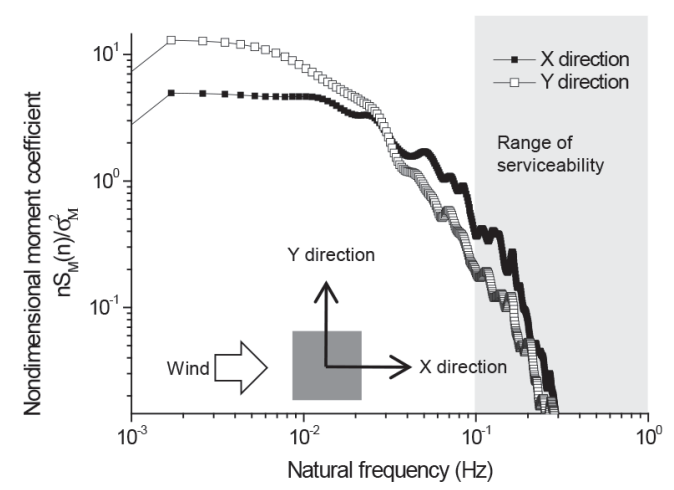

Fig. 1. Typical along-wind and across-wind aerodynamic base moment spectrum 
proportional to the wind-induced vibration of a building, where $n, S_{M}(n)$, and $\sigma_{M}$ are the natural frequency, the power spectral density and the standard deviation of the overturning moment, respectively. The spectrum in Figure 1, within the range of $0.1 \sim 1.0 \mathrm{~Hz}$ corresponding to the range of the natural frequencies of high-rise buildings, shows that the spectrum values decrease as the values of the natural frequency increase. This means that the wind-induced responses can be reduced by increasing the natural frequency of a high-rise building.

\section{Resizing algorithm}

The resizing algorithm is used to increase the natural frequency of a high-rise building by improving the stiffness of the building (Park, H. S., Park, C. L. 1997; Park et al. 2008; Seo et al. 2008). In the resizing algorithm, to increase the natural frequency of a high-rise building, the stiffness of the building structure is improved by reducing the lateral displacement at the top of the building without increasing the weight of the structure. Because the maximum values of displacement and acceleration, which are used as indexes for serviceability evaluations, occur at the top of the building, the resizing algorithm minimizes the displacement of the top of the building. Generally, the maximum acceleration of buildings is proportional to the maximum displacement of buildings. The displacement participation factor defined by each member's contribution to the displacement to be reduced consists of six components: axial, bending ( $\mathrm{Y}$ and $\mathrm{Z}$ local axes), shear ( $\mathrm{Y}$ and $\mathrm{Z}$ local axes), and torsional displacement components. Based on the calculated member displacement participation factors, active members can be selected to reduce the displacement and the cross sections of the active members can be modified for effective control of the displacement. To reduce the displacement without increasing the weight of the structure, a certain portion of structural material in the non-active members may be taken out and added to the active members. The amount of material to be resized depends on the member displacement factors and is determined by resizing algorithms formulated in the form of an optimization problem.

In the formulation of the resizing module, the objective function is expressed in terms of the displacement to be reduced and minimized with the assumption that the displacement participation factor of each member is inversely proportional to the change in weight of the member:

$$
\begin{aligned}
& \text { Minimize } \quad \sum_{i=1}^{m} \frac{\delta_{i}}{\beta_{i}}= \\
& \sum_{i=1}^{m} \frac{1}{\beta_{i}} \int_{0}^{l_{i}}\left(\frac{F_{X} f_{X}}{E A}+\frac{F_{Y} f_{Y}}{G A_{Y}}+\frac{F_{Z} f_{Z}}{G A_{Z}}+\right. \\
& \left.+\frac{M_{X} m_{X}}{G I_{X}}+\frac{M_{Y} m_{Y}}{E I_{Y}}+\frac{M_{Z} m_{Z}}{E I_{Z}}\right)_{i} \mathrm{~d} x ;
\end{aligned}
$$

$$
\text { Subject to } \gamma \sum_{i=1}^{m} \rho_{i} A_{i} l_{i}=\sum_{i=1}^{m} \rho_{i}\left(\beta_{i} A_{i}\right) l_{i}
$$

where: $\delta_{i}$ and $\beta_{i}$ are the displacement participation factor and the weight modification factor of the $i$-th member, respectively. The cross section of the $i$-th member is resized according to $\beta_{i} ; m$ is the total number of members in a structure and $l_{i}$ is the length of the $i$ th member; $E$ and $G$ are the modulus of elasticity and the shear modulus of elasticity, respectively; $A, A_{Y}$, and $A_{Z}$ are the axial and shear areas of the cross section; $I_{X}, I_{Y}$, and $I_{Z}$ are the torsional and flexural moments of inertia for the cross section; $F_{X}, F_{Y}, F_{Z}, M_{X}, M_{Y}$, and $M_{Z}$ are the member forces and moments due to the wind load; $f_{X}, f_{Y}, f_{Z}, m_{X}, m_{Y}$, and $m_{Z}$ are the member forces and moments due to the unit load at the top of the structure; $\rho_{i}$ is the weight density of the $i$ th member. In Eqn (2), $\gamma$ is the total weight control factor to control the total weight of the structure. If the value of $\gamma$ is set to 1.0 , the displacement at the top of the building is minimized on the condition that there is no change in the total weight of the structure before and after resizing. Using the weight control factor, the relationship between the natural frequency and weight for a high-rise building can be obtained. The relationship between the natural frequency and the total weight for a high-rise building may allow structural engineers to estimate adequate structural weights in order to obtain the maximum natural frequency.

Eqns (1) and (2) are transformed into the unconstrained minimization problem in Eqn (3) by introducing the Lagrange multiplier:

$$
\text { Minimize } \delta_{t}=\sum_{i=1}^{m} \frac{\delta_{i}}{\beta_{i}}+\lambda\left\{\sum_{i=1}^{m}\left(\beta_{i} W_{i}-\gamma W_{i}\right)\right\}
$$

where: $\delta_{i}$ and $\lambda$ are the transformed pseudo objective function and the Lagrange multiplier, respectively; $W_{i}$ is $\rho_{i} A_{i} l_{i}$. Taking derivatives of the Eqn (3) with respect to $\beta_{i}$ and $\lambda$ and setting them to zero, the weight modification factor $\beta_{i}$ of the $i$-th member is given in Eqn (4):

$$
\beta_{i}=\gamma \sqrt{\frac{\delta_{i}}{W_{i}}} \frac{\sum_{i=1}^{m} W_{i}}{\sum_{i=1}^{m} \sqrt{\delta_{i} W_{i}}} .
$$

If the value of the displacement participation factor of the $k$-th member is relatively larger than the values of other members, the value of the weight modification factor of the $k$-th member becomes greater than 1.0. Based on the values of the weight modification factors of the members, the resizing module in this paper increases the stiffness of a building by changing the cross sections of the members. 


\section{Application to control the wind-induced vibration of a high-rise building}

\subsection{Model for controlling the wind-induced responses of a high-rise building}

By combining the structural analysis module, the windinduced vibration evaluation method, and the resizing algorithm with the weight modification factors, the design model to control the wind-induced responses of a high-rise building proposed in this paper is shown in Figure 2. For a given preliminary design satisfying the strength requirements based on design specifications, the level of wind-induced vibration of a high-rise building is estimated. If the estimated wind-induced responses of the preliminary design do not satisfy the serviceability requirements, the cross sections of members are resized according to the modification factors in Eqn (4) in the steps 6-9 in Figure 2. At this step, although the calculated wind-induced responses satisfy the serviceability requirement, the cross sections of members may be resized to reduce the total weight of the structure by specifying the values of the weight control factor in Eqn (2). In the final step, the strength requirements of resized members are checked using the modified cross sections.

In this study, it is assumed that the member forces are constant despite the fact that the cross sections of members are changed by the proposed method. In the indeterminate structures, the member forces are changed according to the cross sections of members. However, in high-rise buildings, the changes of the member forces ac-

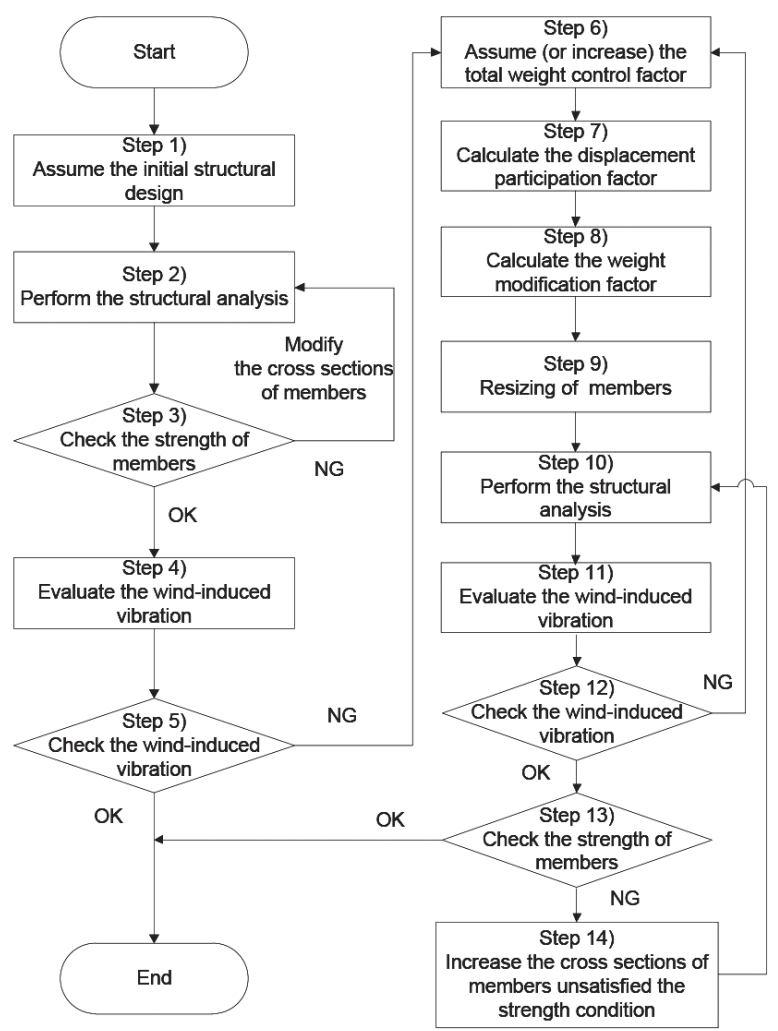

Fig. 2. Design model to control the wind-induced responses of a high-rise building cording to the changes in the cross sections of the members are small (Baker 1990; Charney 1991). Therefore, it can be assumed that the member forces are constant in the resizing algorithm.

\subsection{Actual 37-storey building structure}

The proposed design method is applied to the control of the wind-induced vibration of a 37-storey residential complex building structure built in 2003. As shown in Figures 3 and 4, the height, width, and depth of the building are $127.2 \mathrm{~m}, 27.4 \mathrm{~m}$ and $28.2 \mathrm{~m}$, respectively.

This example is located in a downtown area with the stiff soil (soil profile type S2, AIK 2000). The shear wall, outrigger, and flat plate are used as its structural system. As the lateral load resisting system, outriggers are

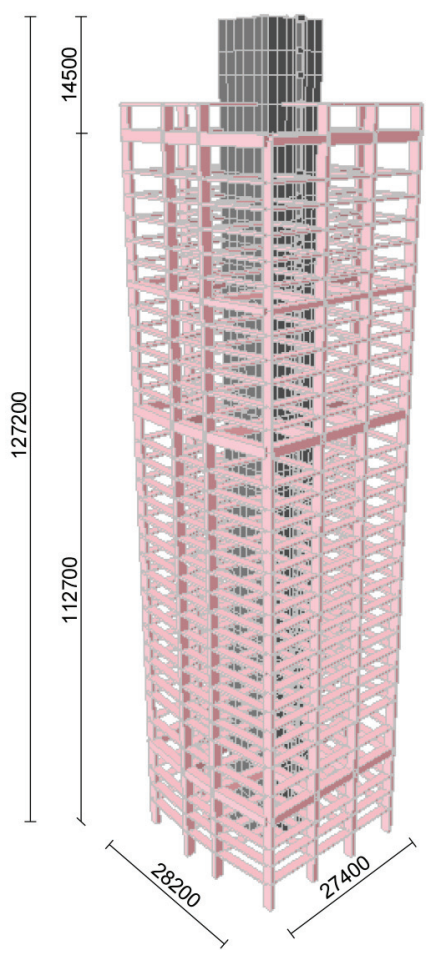

Fig. 3. Perspective view of the 37 -storey building

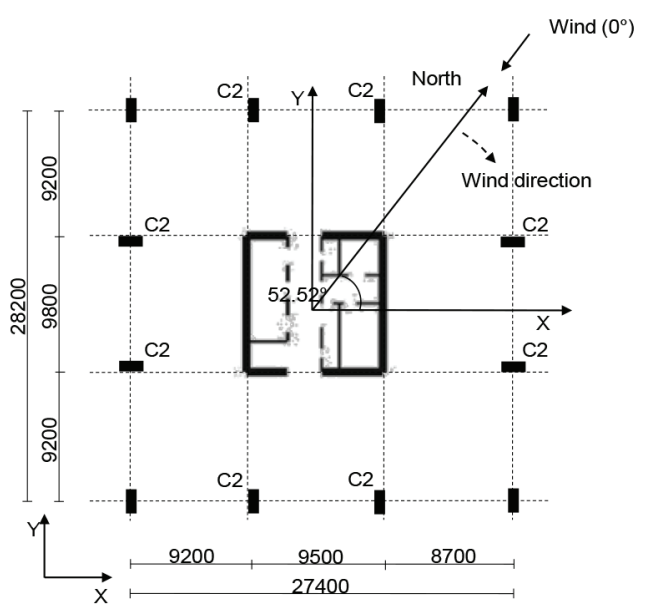

Fig. 4. Plan view of the 37-storey building 
installed at 5, 22, and 34 storey levels. For structural analysis of the model, the Midas Gen software (MIDAS 2012) is used. The structural nodes at the supports located at the base are fixed in every direction. In the modelling, 1,986 different beam-type elements are used to model structural members for beams and columns. In the wall members, 1,978 wall-type elements are used. For this example, reinforced concrete with three different levels of the compressive strength of 27, 35, and $40 \mathrm{MPa}$ are used. Every joint is modelled as a rigid joint. At every floor, the diaphragm effect is considered. The interaction between the ground and structure, the long-term loading effect, and the ground settlement of ground are not considered. In this study, the dead load, live load, earthquake load, and wind load are considered, and the earthquake load and wind load are calculated according to the AIK specifications (2000). To calculate the member forces and deformation of the structure, a linear static analysis is performed and KCI (2003) is used for the structural design.

The lateral load resisting structural system used in this example is the outrigger system. In the outrigger system, the key elements to resist the lateral load are shear wall, outrigger, and external columns. Therefore, in this study, the shear wall, the outrigger, and the columns are considered in the resizing algorithm, while flat plates as a vertical load resisting structural system are not considered in the resizing algorithm. The sections of flat plates do not change before and after the application of the resizing algorithm.

This example satisfies with the acceptance criteria of NBCC (1995), which are 10 and $30 \mathrm{mg}$ for a resident and office building, respectively. Therefore, if the optimal model presented in section 3.1 is used, the resizing method would be not necessary in this example because the wind-induced vibration condition is satisfied. However, to evaluate the efficiency of this optimal model, the resizing method was applied only once, and then the results of the preliminary design and the final design obtained from the proposed model were compared.

In the process of the resizing, the total weight control factor $\gamma$ is set to 1.0 so that the total structural weight is not changed before and after the application of the resizing algorithm. The displacement participation factors of the columns, beams, and shear walls are then computed and used for the calculation of the modification factors $\beta_{i}$ for the structural members as defined in Eqn (4). The weights according to the members of the preliminary design (step 1), the design after resizing (step 9), and the final design after a strength check (step 14) are summarized in Table 1. The resizing method in this study uses continuous sections as a design variable. Therefore, the sections determined by the resizing method may be impractical sections and it may be necessary to modify these sections. Also, in this study, to prevent the thickness of shear wall from becoming impractical, a constraint condition stating that the thickness of the shear wall will change within $30 \%$ is additionally set. For these reasons, although the total weight control factor is set to 1.0 , the weight of the design after resizing is reduced to $0.94 \%$ compared to the weight of preliminary design. The weight of the design after the strength check is increased to $0.74 \%$ compared to the weight of the design after resizing and is decreased to $0.21 \%$ compared to the weight of the preliminary design. As shown in Table 1, the weight of the outrigger is moved to the weight of shear wall. The sections of column C2 in Figure 4 and the shear wall in the preliminary design and the design after the strength check along with the height are shown in Figures 5 and 6, respectively. The sections of the column and shear wall are increased at the lower level and are decreased at the upper level. Thus, the weight of the lower level increases and the weight of the upper level decreases, as shown in Figure 7. The maximum lateral displacements of the preliminary design and the design after the strength check are summarized in Table 2. The maximum displacements of $215.90 \mathrm{~mm}$ and $183.70 \mathrm{~mm}$ are decreased to $179.80 \mathrm{~mm}$ and $159.00 \mathrm{~mm}$ in the $\mathrm{X}$ and Y directions, respectively. The distribution of the lateral displacement of the building is shown in Figure 8.

In this paper, the resizing method is adopted to increase the natural frequency of the building for the control of the wind-induced response of the building. The natural frequencies of the building structure in the $\mathrm{X}$ and $\mathrm{Y}$ di-

Table 1. Weight change of the example according to the application of the resizing method (Unit: $\mathrm{MN}$ )

\begin{tabular}{lcccc}
\hline & Columns & $\begin{array}{c}\text { Outriggers } \\
\text { (beams) }\end{array}$ & $\begin{array}{c}\text { Shear } \\
\text { wall }\end{array}$ & Sum \\
\hline Preliminary & 46.25 & 81.45 & 78.95 & 206.66 \\
\hline $\begin{array}{l}\text { After } \\
\text { resizing }\end{array}$ & 46.47 & 77.34 & 80.92 & 204.72 \\
\hline $\begin{array}{l}\text { After } \\
\text { strength } \\
\text { check }\end{array}$ & 47.98 & 77.34 & 80.92 & 206.23 \\
\hline
\end{tabular}

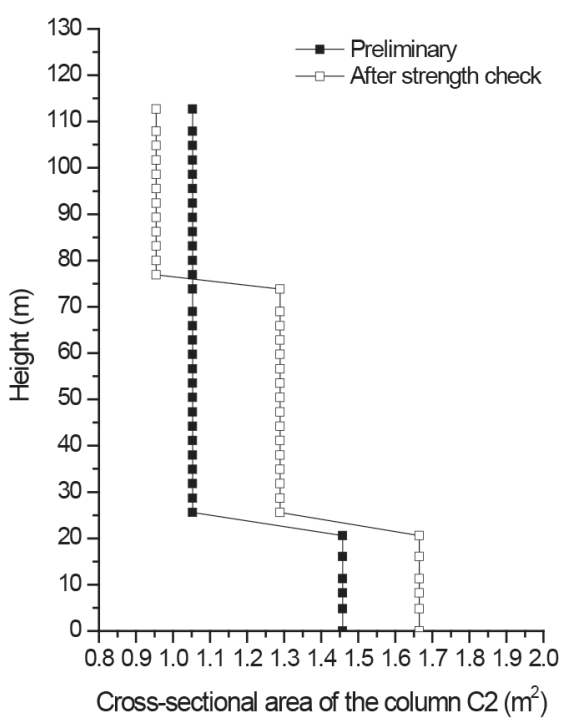

Fig. 5. Changes in the cross sections of column $\mathrm{C} 2$ 


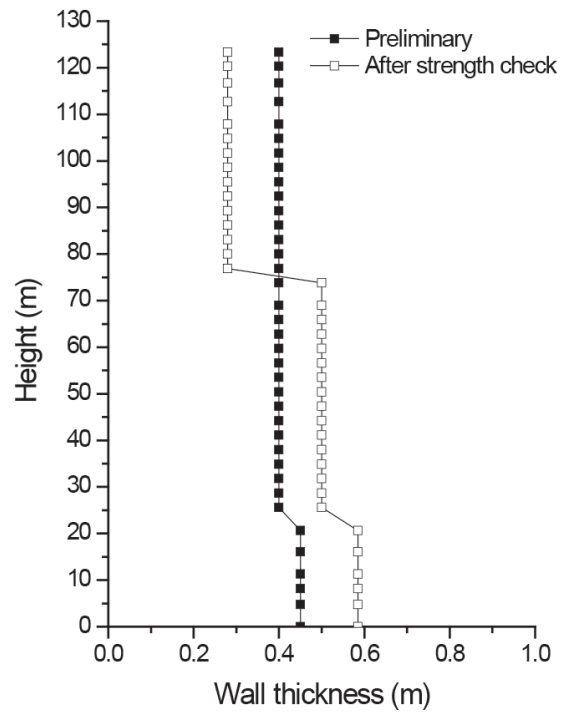

Fig. 6. Changes in the wall thickness

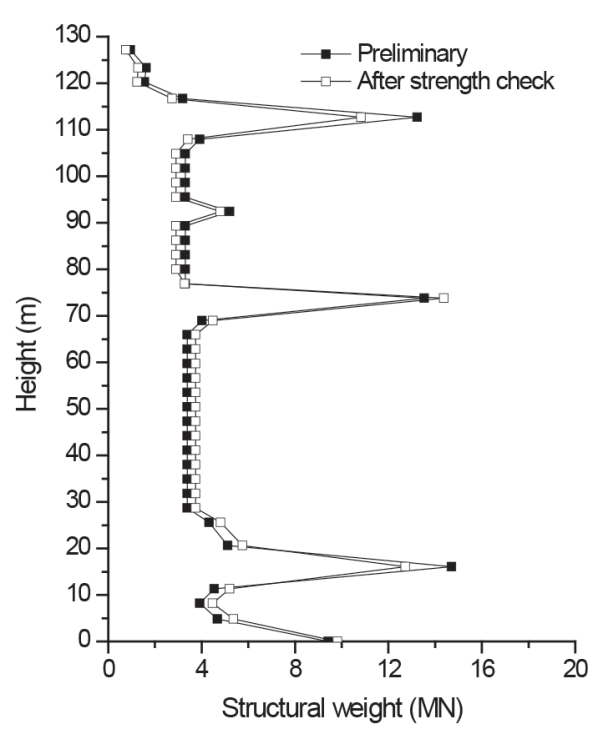

Fig. 7. Changes in the storey weights

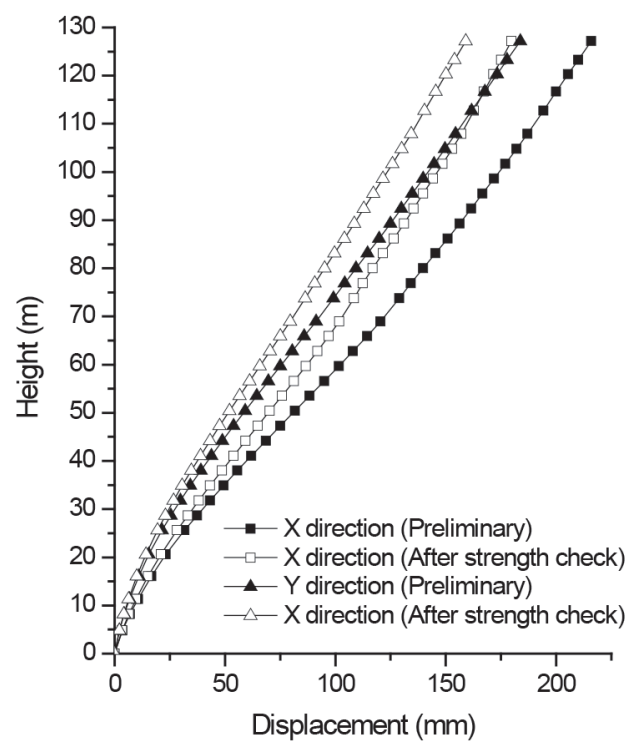

Fig. 8. Distribution of the lateral displacements through the height of the structure

rections are listed in Table 3. The natural frequencies of $0.2252 \mathrm{~Hz}$ and $0.2572 \mathrm{~Hz}$ are increased to $0.2466 \mathrm{~Hz}$ and $0.2792 \mathrm{~Hz}$ in the $\mathrm{X}$ and $\mathrm{Y}$ directions, respectively, showing increases of $9.50 \%$ and $8.55 \%$. Therefore, it is expected that the design model with the resizing algorithm will provide a design with controlled wind-induced responses.

\subsection{Wind-induced responses}

To evaluate the efficiency of the proposed model, the wind-induced responses of the 37-storey building structure before and after the application of the model are estimated by the two methods discussed in Section 1.

For the evaluation of the responses by the simplified equations (NBCC 1995), the density and damping ratio in the $\mathrm{X}$ and $\mathrm{Y}$ directions of the building are given by $361.98 \mathrm{~kg} / \mathrm{m}^{3}$ and $2 \%$, respectively. The estimated wind-induced vibrations according to the simplified equation in NBCC (1995) are summarized in Table 4. The peak accelerations in both the along-wind and cross-wind directions of $5.92 \mathrm{mg}$ and $7.56 \mathrm{mg}$ are reduced to $5.39 \mathrm{mg}$ and $6.81 \mathrm{mg}$, respectively.

Table 2. Changes in the lateral displacements at the top in the $\mathrm{X}$ and $\mathrm{Y}$ directions

\begin{tabular}{lcccc}
\hline & The maximum lateral displacement $(\mathrm{mm})$ & \multicolumn{2}{c}{$\begin{array}{c}\text { Rate of changes in the maximum lateral } \\
\text { displacement }(\%)\end{array}$} \\
\cline { 2 - 5 } & X direction & Y direction & X direction & Y direction \\
\hline Preliminary & 215.90 & 183.70 & - & - \\
\hline After strength check & 179.80 & 159.00 & -16.72 & -13.45 \\
\hline
\end{tabular}

Table 3. Changes in the natural frequencies of the example by the resizing method

\begin{tabular}{lcccc}
\hline & \multicolumn{2}{c}{ Natural frequency $(\mathrm{Hz})$} & \multicolumn{2}{c}{ Rate of changes in natural frequency (\%) } \\
\cline { 2 - 5 } & X direction & Y direction & X direction & Y direction \\
\hline Preliminary & 0.2252 & 0.2572 & - & - \\
\hline After strength check & 0.2466 & 0.2792 & 9.50 & 8.55 \\
\hline
\end{tabular}


After the strength check (step 14), the along-wind peak acceleration is reduced by $8.87 \%$ while the natural frequency is increased by $9.50 \%$ in the $\mathrm{X}$ direction. The cross-wind peak acceleration is reduced by $9.91 \%$ where the natural frequency is increased by $8.55 \%$ in the $\mathrm{Y}$ direction. These results are in accord with the fact that the level of the wind-induced vibration can be assumed to be inversely proportional to the natural frequency of the building (Tallin, Ellingwood 1984; Griffis 1993).

For the evaluation of the wind-induced vibration by the HFFB method, a wind-tunnel test was performed. A boundary layer wind tunnel with a closed circuit type was used. The width, height and length of the tunnel are $3 \mathrm{~m}, 2 \mathrm{~m}$, and $20 \mathrm{~m}$, respectively. The range of the wind velocity measureable by the tunnel is 0.5 to $30 \mathrm{~m} / \mathrm{s}$. A power law for the profile of the wind velocity was used. The decay coefficient for a decrease in the speed-up with the height is 0.33 . The scale of the model is $1 / 400$ and the reproduction range of the surrounding area has a $400 \mathrm{~m}$ radius with a design-scale model as the center. The windtunnel test was performed 36 times at $10^{\circ}$ angle intervals. The reference axis for the angle of the wind direction is shown in Figure 4. The time-varying wind loads were measured by a six-component force balance installed at the bottom of the design-scale model. The sampling frequency was set equal to $200 \mathrm{~Hz}$ for a total of $51.2 \mathrm{sec}$. The maximum hourly mean wind velocity with a return period of 10 years was used for the serviceability evaluation. The roughness and design velocity for the serviceability evaluation were A and $26.76 \mathrm{~m} / \mathrm{s}$, respectively. Using the spectrum data obtained from the experiment as shown in Figure 1, the wind-induced response of the building after the strength check (step 14) was evaluated. Figure 7 shows the spectrum data of a wind direction of $150^{\circ}$ which generates the highest wind-induced acceleration among 36 directions. The results of the evaluation of the wind-induced vibration for the preliminary design and for the design after the strength check are shown in Figure 9 . The peak accelerations of $9.95 \mathrm{mg}$ and $9.69 \mathrm{mg}$ are decreased to $9.60 \mathrm{mg}$ and $8.23 \mathrm{mg}$, respectively. The peak accelerations are decreased by $3.48 \%$ and $15.04 \%$ in the $\mathrm{X}$ and $\mathrm{Y}$ directions, respectively. As shown in Figure 9, the wind-induced vibrations are generally decreased by the proposed optimal model. However, as shown in Figures 9 and 10, the wind-induced vibrations in some directions are increased, indicating that an increase in the natural frequency does not always result in a decrease of the wind-induced vibration. This is due to the property of the wind force spectrum. As shown in Figure 11, although the wind force spectrum of 0.0493 in the $\mathrm{X}$ direction is
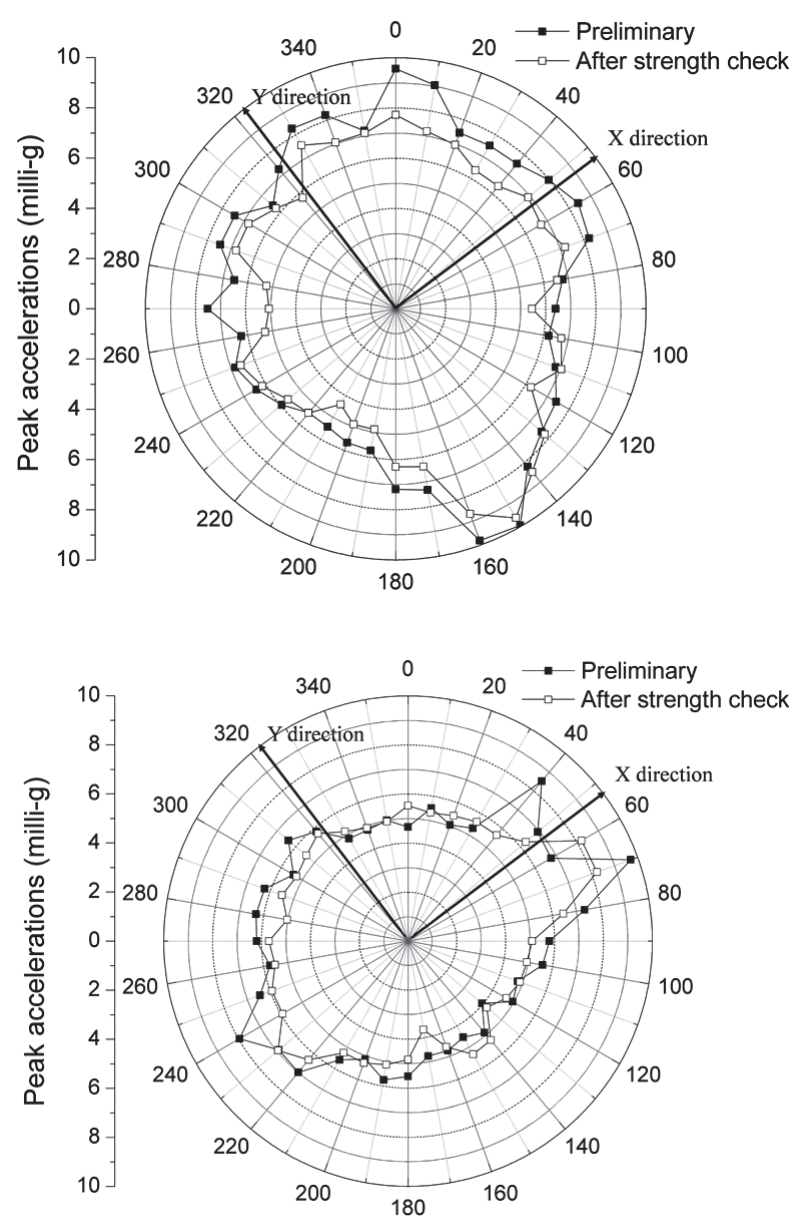

Fig. 9. Peak accelerations according to the wind direction

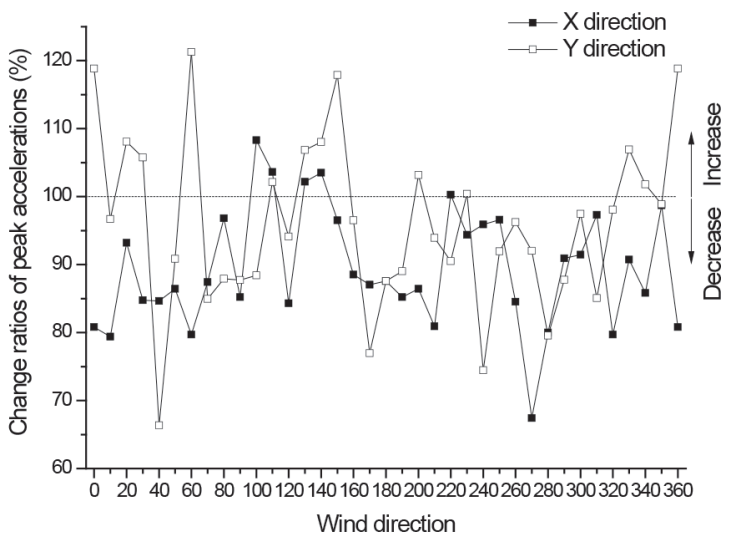

Fig. 10. Reduction ratios of the maximum acceleration after applying the resizing method

Table 4. The results of the wind-induced response obtained from simplified equations in NBCC

\begin{tabular}{ccccc}
\hline & \multicolumn{2}{c}{ Peak accelerations $(\mathrm{mg})$} & \multicolumn{2}{c}{ Change of the peak accelerations (\%) } \\
\cline { 2 - 5 } & X direction & Y direction & X direction & Y direction \\
\hline Preliminary & 5.92 & 7.56 & - & - \\
\hline After strength check & 5.39 & 6.81 & -8.87 & -9.91 \\
\hline
\end{tabular}


decreased to 0.0425 , the wind force spectrum of 0.0135 in the $\mathrm{Y}$ direction is increased to 0.0174 . Therefore, the peak acceleration of $9.95 \mathrm{mg}$ in the $\mathrm{X}$ direction is decreased to $9.60 \mathrm{mg}$ and the peak acceleration of $4.52 \mathrm{mg}$ in the $\mathrm{Y}$ direction is increased to $5.33 \mathrm{mg}$. This is why the wind force spectrum is generally decreased along with the natural frequency, but not always. In contrast, in the case for NBCC 1995, the wind-induced vibration could always be reduced by increasing the natural frequency, as shown in Figure 12.

\section{Conclusions}

A practical design model based on the resizing algorithm is presented to control of the wind-induced responses of a high-rise building. In the model, to reduce the windinduced responses, the stiffness of a high-rise building is maximized to increase the natural frequency of the building by the resizing algorithm. The proposed design model is applied to control the wind-induced vibration of an actual 37-storey building during the initial stage of its structural design.

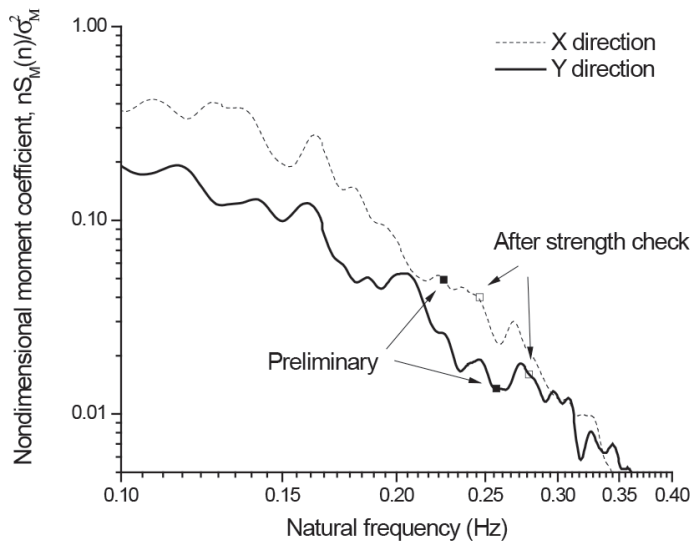

Fig. 11. Comparison of the wind force spectrum as measured by HFFB

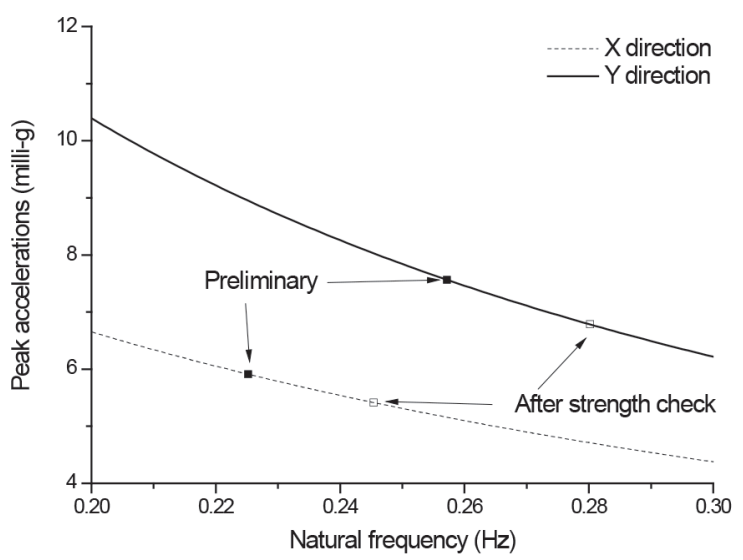

Fig. 12. Comparison of the wind-induced vibration as evaluated by NBCC 1995
From the evaluation of the wind-induced vibrations by both the simplified method in NBCC and the HFFB method, the wind-induced vibration for an actual 37 -storey building was successfully reduced by the design model. Also, contrary to the findings of existing research (Chan, Chui 2006; Chan et al. 2009, 2010; Li et al. 2011), all of which require an iterative structural analysis, the proposed design model based on resizing algorithm can obtain this effect without an iterative structural analysis.

The wind load applied to the building changes according to the natural frequency of the building. However, this study used the calculation process of the wind load in AIK (2000), which does not consider the influence of the natural frequency of the building. As the wind load applied to a building generally increases along with the natural frequency of the building, considering this effect during the optimization process is expected to result in an additional reduction of the structural weight. A study of the optimal design model for the wind-induced vibration of a high-rise building considering this effect will be carried out as a continuation of research.

\section{Acknowledgments}

This work was supported by the National Research Foundation of Korea (NRF) grant funded by the Korea government (MEST) (No. 2012-0001247).

\section{References}

AIJ (Architectural Institute of Japan). 2004. Recommendations for loads on buildings. Tokyo.

AIK (Architectural Institute of Korea). 2000. Standard design loads for buildings. Korea.

ASCE (American Society of Civil Engineers). 2006. Minimum design loads for building and other structures. ASCE 7-05. New York.

Baker, W. F. 1990. Sizing techniques for lateral systems in multi-story steel buildings, in Proceedings of $4^{\text {th }}$ World Congress on Tall Building: 2000 and Beyond, 5-9 November 1990, Council on Tall Buildings and Urban Habitat (CTBUH), Hong Kong.

Boggs, D. 1997. Acceleration indexes for human comfort in tall buildings - Peak or RMS?, CTBUH Monograph.

Cermak, J. E. 2003. Wind-tunnel development and trends in applications to civil engineering, Journal of Wind Engineering and Industrial Aerodynamics 91(3): 355-370. http://dx.doi.org/10.1016/S0167-6105(02)00396-3

Chan, C. M.; Chui, J. K. L. 2006. Wind-induced response and serviceability design optimization of tall steel buildings, Engineering Structures 28(4): 503-513.

http://dx.doi.org/10.1016/j.engstruct.2005.09.005

Chan, C. M.; Huang, M. F.; Kwok, K. C. S. 2009. Stiffness optimization for wind-induced dynamic serviceability design of tall buildings, Journal of Structural Engineering ASCE 135(8): 985-997.

http://dx.doi.org/10.1061/(ASCE)ST.1943-541X.0000036

Chan, C. M.; Huang, M. F.; Kwok, K. C. S. 2010. Integrated wind load analysis and stiffness optimization of tall buildings with 3D modes, Engineering Structures 32(5): 12521261. http://dx.doi.org/10.1016/j.engstruct.2010.01.001 
Charney, F. A. 1991. The use of displacement participation factors in the optimization of drift controlled buildings, in Proceedings of $2^{\text {nd }}$ Conference on Tall Buildings in Seismic Regions, 55 ${ }^{\text {th }}$ Regional Conference, 16-17 May 1991, Los Angeles, CA.

Griffis, L. G. 1993. Serviceability limit states under wind load, Engineering Journal AISC 30(1): 1-16.

ISO 6897: 1984 Guidelines for the fixed structures, especially buildings and off-shore structures to low-frequency horizontal motion (0.063 to $1 \mathrm{~Hz}$ ). International Organization for Standardization.

Kareem, A.; Kijewski, T.; Tamura, Y. 1999. Mitigation of motions of tall buildings with specific examples of recent applications, Wind and Structures 2(3): 201-251. http://dx.doi.org/10.12989/was.1999.2.3.201

KCI (Korea Concrete Institute). 2003. Structural Concrete Design Code. Korea.

Kijewski, T.; Kareem, A. 1998. Dynamic wind effects: a comparative study of provisions in codes and standards with wind tunnel data, Wind and Structures 1(1): 77-109. http://dx.doi.org/10.12989/was.1998.1.1.077

Kijewski, T.; Pirnia, J. D. 2007. Dynamic behavior of tall buildings under wind: insights from full-scale monitoring, The Structural Design of Tall and Special Buildings 16(4): 471-486. http://dx.doi.org/10.1002/tal.415

Kim, Y. C.; Kanda, J. 2008. Wind response characteristics for habitability of tall buildings in Japan, The Structural Design of Tall and Special Buildings 17(3): 683-718. http://dx.doi.org/10.1002/tal.373

Lee, K.; Ricles, J.; Sause, R. 2009. Performance-based seismic design of steel MRFs with elastomeric dampers, Journal of Structural Engineering ASCE 135(5): 489-498.

http://dx.doi.org/10.1061/(ASCE)0733-9445(2009)135:5(489)

Lewandowski, R.; Grzymislawska, J. 2009. Dynamic analysis of structures with multiple tuned mass dampers, Journal of Civil Engineering and Management 15(1): 77-86. http://dx.doi.org/10.3846/1392-3730.2009.15.77-86

Li, Q. S.; Zou, X. K.; Wu, J. R.; Wang, Q. 2011. Integrated wind-induced response analysis and design optimization of tall steel buildings using Micro-GA, The Structural Design of Tall and Special Buildings 20(8): 951-971. http://dx.doi.org/10.1002/tal.569

Marshall, J. D.; Charney, F. A. 2012. Seismic response of steel frame structures with hybrid passive control systems, Earthquake Engineering and Structural Dynamics 41(4): 715-733.

http://dx.doi.org/10.1002/eqe.1153

MIDAS/Gen Program 2012. MIDAS/Gen-General structure design system [online], [cited 17 April 2012]. MIDAS
Information Technology, Co., Ltd. Available from Internet: http://www.midasit.com

NBCC (National Building Code of Canada). 1995. National building code of Canada (NBCC), Part 4 and Commentary C. Ottawa.

Park, H. S.; Park, C. L. 1997. Drift control of high-rise buildings with unit load method, The Structural Design of Tall and Special Buildings 6(3): 23-25. http://dx.doi.org/10.1002/ (SICI)1099-1794(199703)6:1<23::AID-TAL80>3.0.CO;2-1

Park, H. S.; Seo, J. H.; Kwon, Y. H. 2008. Development of drift design model for high-rise buildings subjected to lateral and vertical loads, The Structural Design of Tall and Special Buildings 17(2): 273-293. http://dx.doi.org/10.1002/tal.351

Patil, V. B.; Jangid, R. S. 2011. Optimum multiple tuned mass dampers for the wind excited benchmark building, Journal of Civil Engineering and Management 17(4): 540557. http://dx.doi.org/10.3846/13923730.2011.619325

Petrini, F.; Ciampoli, M. 2012. Performance-based wind design of tall buildings, Structure and Infrastructure Engineering 8(10): 954-966.

Sayani, P. J.; Erduran, E.; Ryan, K. L. 2011. Comparative response assessment of minimally compliant low-Rise base-isolated and conventional steel moment-resisting frame buildings, Journal of Structural Engineering ASCE 137(10): 1118-1131. http://dx.doi.org/10.1061/(ASCE)ST.1943-541X.0000358

Seo, J. H.; Song, W.; Kwon, Y. H.; Hong, K.; Park, H. S. 2008. Drift design model for high-rise buildings based on resizing algorithm with a weight control factor, The Structural Design of Tall and Special Buildings 17(3): 563-578. http://dx.doi.org/10.1002/tal.366

Solari, G. 1982. Alongwind response estimation: closed form solution, Journal of Structural Division ASCE 108(1): 225-244.

Taflanidis, A. A.; Jia, G. 2011. A simulation-based framework for risk assessment and probabilistic sensitivity analysis of base-isolated structures, Earthquake Engineering and Structural Dynamics 40(14): 1629-1651. http://dx.doi.org/10.1002/eqe.1113

Tallin, A.; Ellingwood, B. 1984. Serviceability limit states: wind induced vibrations, Journal of Structural Engineering ASCE 110(10): 2424-2437.

http://dx.doi.org/10.1061/(ASCE)0733-9445(1984)110:10(2424)

Tschanz, T.; Davenport, A.G. 1983. The base balance technique for the determination of dynamic wind loads, Journal of Wind Engineering and Industrial Aerodynamics 13(1-3): 429-439. http://dx.doi.org/10.1016/0167-6105(83)90162-9

Se Woon CHOI. An Assistant Professor at the Department of Architecture, Catholic University of Daegu. He received his PhD degree in Architectural Engineering from Yonsei University. His main research interest is the design of large-scale structures and structural optimization.

Ji Hyun SEO. A Senior Researcher at the GS E\&C Research Institute, South Korea. He received his PhD degree in Architectural Engineering from Yonsei University. His main research interest is the drift design of large-scale structures and structural optimization.

Hong Min LEE. A Senior Engineer at the Samsung Engineering, South Korea. He received his PhD degree in Architectural Engineering from Yonsei University. His main research interest is the structural health monitoring and structural optimization.

Yousok KIM. A Research Professor at the Yonsei University, South Korea. He received his PhD degree in Architectural Engineering from University of Tokyo. His main research interest is the seismic design of reinforced concrete buildings.

Hyo Seon PARK. A Professor at the Department of Architectural Engineering, Yonsei University, South Korea. He received his $\mathrm{PhD}$ degree in Civil Engineering from The Ohio State University. His main research interest is the design of high-rise buildings, structural optimization, structural health monitoring. 